\title{
Profile of the horizontal wind variance near the ground in near neutral flow - K-theory and the transport of the turbulent kinetic energy
}

\author{
S. Yahaya ${ }^{1, *}$ and J. P. Frangi ${ }^{1}$ \\ ${ }^{1}$ Equipe Géomatériaux \& Environnement, Institut de Physique du Globe de Paris/Université Paris 7 - Denis Diderot, UMR \\ 7154, case postale 89, 4 place Jussieu 75252 Paris cedex 05, France \\ * current address: National Centre of Solar Energy (CNES), BP 621, Niamey, Niger
}

Received: 7 April 2008 - Revised: 9 February 2009 - Accepted: 27 February 2009 - Published: 4 May 2009

\begin{abstract}
This paper deals with the characteristics of the atmospheric turbulent flow in the vicinity of the ground, and particularly with the profile of the horizontal wind variance. The study is based on experimental measurements performed with fast cup anemometers located near the ground at 5 different levels (from 0.25 to $4 \mathrm{~m}$ ) and sampled at $1 \mathrm{~Hz}$. The experiment was carried over two agricultural plots with various tillage treatments in a fallow semiarid area (Central Aragon, Spain). The results of this study reveal that near the ground surface and under moderate wind, the horizontal wind variance logarithmically increases with height, in direct relationship with the friction velocity and the roughness length scale. A theoretical development has allowed us to link this behaviour to the modeling of the turbulent kinetic energy (TKE) transport through the eddy diffusivity. Thus, the study proposes a formulation of the similarity universal function of the horizontal wind variance. Besides, the formulation offers a new method for the determination of the friction velocity and the roughness length scale and can be used for the evaluation of the TKE transport rate.
\end{abstract}

Keywords. Meteorology and atmospheric dynamics (Turbulence; Instruments and techniques; General or miscellaneous)

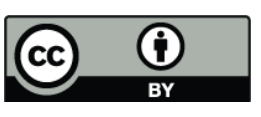

Correspondence to: J. P. Frangi (jean-pierre.frangi@univ-parisdiderot.fr)

\section{Introduction}

The wind velocity variance, which represents the turbulent kinetic energy (TKE), is an important parameter of the atmospheric surface layer (ASL) since it conditions many phenomena taking place in this layer, such as the diffusion of chemical and physical aerosols, energy transfer between the mean and the turbulent flows, heat and mass transfer, extreme wind force exercised on structures, etc.

Despite the existence of long established relationships (Panofsky et al., 1977), the behaviour of the variance of the horizontal wind components in the ASL stills discussed, specially the definition of their pertinent scaling parameters. In this very specific study, which concerns the very lower layer of the ASL, also called the "eddy surface layer (ESL)" (see Hunt and Carlotti, 2001), one has to highly consider the definition of the pertinent parameters.

In this regard, the present study will briefly present some of the literature models, of which some are empirical ones while others stem from well known theories. This will, on one hand, underline the importance of the subject and help in the definition of the pertinent parameters and, on the other hand, provide a base for comparison with the developed results.

Then, the paper will develop a range of equations showing, very near the ground, that the horizontal wind variance (or the horizontal component of the kinetic energy) is a function of the vertical coordinate $z$. Then, a logarithmic profile model will be proposed for the variation of the variance.

The model will then be validated with data deriving from WELSONS (Wind Erosion and Losses of Soil Nutrients in semiarid Spain), which is a European research project

Published by Copernicus Publications on behalf of the European Geosciences Union. 
devoted to the study of desertification and land degradation by wind erosion in the European Mediterranean area (Frangi and Richard, 2000; Gomes et al., 2003) (see also Sect. 4).

\section{Some bibliographical recalls}

For Kaimal and Finnigan (1994), the horizontal wind components, contrary to the vertical one, are not governed by the Monin-Obukhov ASL similarity theory, which states that various atmospheric parameters and statistics, such as gradients, variances and co-variances, when normalized by appropriate powers of the scaling velocity $U_{*}$ and the scaling temperature $\theta_{*}$, become universal functions of the stability parameter, $\zeta=z / L$, where $z$ is the height and $L$ the MoninObukhov length. It is so because the variances of the wind horizontal components do not depend on height throughout the surface layer and most of the ABL, even in highly unstable conditions (Garrat, 1992).

In a study carried out by Hedde and Durand (1994) over the Mediterranean Sea, for heights between 30 and $50 \mathrm{~m}$ and for wind velocity ranging from 6 to $20 \mathrm{~m} / \mathrm{s}$, it was shown that the horizontal wind components followed the similarity theory yielding for free convection:

$$
\frac{\sigma_{u}}{U_{*}}=\frac{\sigma_{v}}{U_{*}}=2.8\left(-\frac{z}{L}\right)^{1 / 3}
$$

Saï (1988) and Idé (1991) reported the same "1/3 power law" with a constant of 2.0 and 5.4, respectively, instead of 2.8. Contrary to the other studies, the latter one was carried out over land, in the semiarid Sahel region of Africa.

Recently, in stable conditions, Pahlow et al. (2001) analysing data from a set of five experiments, distinguished two cases according to the stability parameter. The five experiments were carried out in the ASL at heights ranging from 0.96 to $4.32 \mathrm{~m}$. In weak stability conditions, i.e. when the stability parameter $\zeta \leq 0.1$, they observed that the normalized horizontal wind components adopted a local $z$-less stratification behaviour, thus, becoming constant (Table 1). When the stability parameter exceeds this value, they proposed the following equation:

$$
\frac{\sigma_{i}}{U_{*}}=a+b\left(\frac{z}{L}\right)^{c}
$$

where $i$ represents $u$ and $v . a, b$ and $c$ equal 2.3, 4.3, and 0.5, respectively, for the longitudinal component, and 2.0, 4.0 and 0.6 for the transversal wind.

As reported in Table 1 (i.e., Raupach et al., 1990; Hedde and Durand, 1994), in neutral or near neutral conditions, many authors reported a ratio of 2 between the longitudinal and the transversal variances (Grant, 1986, 1992; Drobinski et al., 2004).
For turbulence in near-neutral ASL, Solari (1987) proposed a relationship in which the normalised longitudinal variance, $\beta_{u}$, depends on the terrain roughness, $Z_{0}$, i.e.:

$$
\beta_{u}=\frac{\sigma_{u}^{2}}{U_{*}^{2}}=\left\{\begin{array}{cll}
7.5 & \text { for } & Z_{0} \leq 0.03 \\
4.5-0.856 \ln \left(Z_{0}\right) & \text { for } & 0.03 \leq Z_{0} \leq 1 \\
4.5 & \text { for } & Z_{0} \geq 1
\end{array}\right.
$$

where $Z_{0}$ is expressed in meters.

In a recent study, Carlotti (2001) proposed a pure blocking Rapid Distortion Theory (RDT) model adapted for sheared neutral boundary layers and taking into account a -1 intermediate subrange in the longitudinal velocity $\operatorname{spectrum}\left(E_{11}\right)$ only. This model shows:

$$
\left\{\begin{array}{l}
\frac{\overline{u^{\prime 2}}}{\overline{U_{*}^{2}}} \approx \frac{c_{11}}{c_{13}}\left[1+0.5 \ln \left(\frac{\Lambda}{z}\right)\right]+\frac{c_{33}}{c_{13}} \beta_{13}^{2} \\
\frac{v^{\prime 2}}{U_{*}^{2}} \approx \frac{c_{22}}{c_{3}}\left[1+0.5 \ln \left(\frac{\Lambda}{z}\right)\right] \\
\frac{w^{\prime 2}}{U_{*}^{2}} \approx \frac{c_{33}}{c_{13}}
\end{array}\right.
$$

where the constant $c_{i j}$ are of order one, $\Lambda$ is the length scale characterising the lower limit of the -1 range in the spectrum $\left(\Lambda \approx z_{i} U / U_{*}\right.$, see Hunt and Morrison, 2000) and $\beta_{13}$ an unknown shear parameter.

\section{Theoretical background}

The above bibliographical study has allowed for presenting the different theories, concepts and results encountered in the literature related to the modeling of the horizontal wind variance. This section is intended to present a different theoretical approach to the modeling of the horizontal wind variance profile, in ASL.

Departing from the Navier-Stockes equations of the turbulent flow (cf. Appendix A) and assuming the existence of horizontal homogeneity, in order to neglect the horizontal variation of the different parameters, the equation of the horizontal wind fluctuations is (see also Eq. A5):

$2 \overline{u^{\prime} w^{\prime}} \frac{\partial \bar{u}}{\partial z}+\frac{\partial \overline{w^{\prime} u^{\prime 2}}}{\partial z}+\frac{\partial \overline{w^{\prime} v^{\prime 2}}}{\partial z}+2 \varepsilon_{h}=0$

where:

$-\bar{u}$ and $u^{\prime}$ are the mean and the fluctuation of the longitudinal wind velocity

- $v^{\prime}$, the fluctuation of the transversal wind velocity

- $w^{\prime}$, the fluctuation of the vertical wind velocity

- $z$, the vertical coordinate or height

$-\varepsilon_{h}=\varepsilon_{1}+\varepsilon_{2}$, the horizontal components of the TKE dissipation rate, i.e.:

$$
\varepsilon_{1}=v\left[\overline{\left(\frac{\partial u^{\prime}}{\partial x}\right)^{2}}+\overline{\left(\frac{\partial u^{\prime}}{\partial y}\right)^{2}}+\overline{\left(\frac{\partial u^{\prime}}{\partial z}\right)^{2}}\right] \text { and }
$$


Table 1. Variances of the horizontal wind components in neutral and stable conditions in the ASL, according to authors.

\begin{tabular}{|c|c|c|c|c|c|}
\hline Atmospheric conditions & Authors & Specific conditions & $\frac{\sigma_{u}^{2}}{U_{*}^{2}}$ & $\frac{\sigma_{v}^{2}}{U_{*}^{2}}$ & $\frac{\sigma_{u}^{2}+\sigma_{v}^{2}}{U_{*}^{2}}$ \\
\hline \multirow{6}{*}{ Neutral } & \multirow{2}{*}{ Raupach et al. (1990) } & Flat terrain & 5.76 & 3.61 & \\
\hline & & Rolling terrain & 11.56 & 8.41 & \\
\hline & Hedde and Durand (1994) & Over sea & 4.00 & 1.69 & \\
\hline & Stull (1988) & & 6.1 to 6.5 & 2.9 to 6.1 & 8.5 \\
\hline & Drobinski et al. (2004) & Flat terrain $(55 \mathrm{~m})$ & 5 to 6 & 3 & 8 to 9 \\
\hline & Solari (1987) & $Z_{0}<0.03 \mathrm{~m}$ & 7.5 & & \\
\hline \multirow{3}{*}{ Stable } & Moraes and Epstein (1987) & & 4.71 & 3.17 & \multirow{3}{*}{8.5} \\
\hline & Stull (1988) & & - & - & \\
\hline & Pahlow et al. (2001) & $\zeta \leq 0.1$ & 5.29 & 4.0 & \\
\hline
\end{tabular}

$$
\varepsilon_{2}=v\left[\overline{\left(\frac{\partial v^{\prime}}{\partial x}\right)^{2}}+\overline{\left(\frac{\partial v^{\prime}}{\partial y}\right)^{2}}+\overline{\left(\frac{\partial v^{\prime}}{\partial z}\right)^{2}}\right]
$$

$-v$ the viscosity diffusivity

otherwise:

$2 \overline{u^{\prime} w^{\prime}} \frac{\partial \bar{u}}{\partial z}+\frac{\partial\left(\overline{w^{\prime} u^{\prime 2}}+\overline{w^{\prime} v^{\prime 2}}\right)}{\partial z}+2 \varepsilon_{h}=0$

The description of the experimental plots (see Sect. 4.1) and the location of the measurement stations justify the approximation of the transversal homogeneity. Concerning the longitudinal homogeneity, the ratio of the Eulerian length integral scale to the length of the experimental plots (less than $50 \%$ ) broadly justifies this hypothesis.

Regarding the first term of Eq. (5b), for an ASL with constant flux, one has:

$2 \overline{u^{\prime} w^{\prime}} \frac{\partial \bar{u}}{\partial z}=-\frac{2 U_{*}^{3}}{k z}$

where $U_{*}$ is the friction velocity and $k$ the Von Karman's constant, equal to 0.4 .

Then we can come to the second term of Eq. (5b). According to the K-theory, the vertical fluxes of the different ASL parameters are assumed to flow down the local gradient of these parameters. For the specific case of the TKE, this scheme was envisaged by many authors, De Moor (1983), Stull (1988) and Yadav et al. (2003). Thus, we can write:

$\overline{w^{\prime}\left(\left(p^{\prime} / \bar{\rho}\right)+e\right)} \approx \overline{w^{\prime} e}=-K \frac{\partial \bar{e}}{\partial z}$

where $e$ is the TKE, $p^{\prime}$, the pressure fluctuations, $\bar{\rho}$ the mean density and $K$ the eddy diffusivity.

For the horizontal components of the TKE, this can be written in the form:

$\overline{w^{\prime} u^{\prime 2}}+\overline{w^{\prime} v^{\prime 2}}=-K \frac{\partial\left(\overline{u^{\prime 2}}+\overline{v^{\prime 2}}\right)}{\partial z}=-2 K \frac{\partial \overline{e_{h}}}{\partial z}$ where $e_{h}$ is the horizontal component of the TKE, i.e.:

$\overline{e_{h}}=\frac{1}{2}\left(\overline{u^{\prime 2}}+\overline{v^{\prime 2}}\right)$

Third term of Eq. (5b). Considering the fundamental parameters of turbulence and relying on dimensional analysis, André et al. (1978), Louis et al. (1983), and De Moor (1983) come to the formulation of the following relationship:

$\bar{\varepsilon}=\frac{(\bar{e})^{3 / 2}}{l}$

where $l$ is the dissipation length scale. Redelsperger et al. (2001) showed that this relationship can be demonstrated. Their calculation led to a slightly different equation:

$\bar{\varepsilon}=\frac{C_{\varepsilon}}{L}(\bar{e})^{3 / 2}$

where $L$ is a length scale and $C_{\varepsilon}$ a constant. For the horizontal component of the TKE, the previous equation becomes:

$\overline{\varepsilon_{h}}=\frac{C_{\varepsilon}}{L}\left(\overline{e_{h}}\right)^{3 / 2}$

Assuming a light variation of the constants $C_{\varepsilon}$ and $L$.

New form of Eq. (5b). Combining with the previous equations, i.e. Eqs. (6), (7b) and (8c), Eq. (5b) becomes:

$-\frac{U_{*}^{3}}{k z}-\frac{\partial}{\partial z}\left(K \frac{\partial \overline{e_{h}}}{\partial z}\right)+\frac{C_{\varepsilon}}{L}\left(\overline{e_{h}}\right)^{3 / 2}=0$

Parameterization of the eddy diffusivity (cf. Eq. 7a). Relying on the $\bar{e}-\varepsilon$ closure (or $\mathrm{k}-\varepsilon$ closure in the engineering literature) approach, Stull (1988) proposed a parameterization of the eddy diffusivity in the form of:

$K=C_{\varepsilon} \frac{(\bar{e})^{2}}{\bar{\varepsilon}}$

where $C_{\varepsilon}$ is a constant equal to 0.09 .

The previous equation, combined to Eq. (8a), led to:

$K=l C_{\varepsilon}(\bar{e})^{1 / 2}$ 
Redelsperger et al. (2001) deduced the same relationship in the form of:

$K=L C_{K}(\bar{e})^{1 / 2}$

where $C_{K}$ is a constant and $L$ a length scale.

For the horizontal component of the TKE, the previous equation becomes:

$K=L C_{K}\left(\overline{e_{h}}\right)^{1 / 2}$

Thus, Eq. (9) becomes:

$$
-\frac{U_{*}^{3}}{k z}-\frac{2 C_{K}}{3} \frac{\partial}{\partial z}\left(L \frac{\partial\left(\overline{e_{h}}\right)^{3 / 2}}{\partial z}\right)+\frac{C_{\varepsilon}}{L}\left(\overline{e_{h}}\right)^{3 / 2}=0
$$

Combining some equations for the subgrid scheme and for similarity laws, Redelsperger et al. (2001) deduced that the length scale $L$ can be expressed as follows:

$L=k z$

where $k$ is the Von Karman constant.

With Eq. (13), Eq. (12) becomes:

$z \frac{\partial}{\partial z}\left(z \frac{\partial\left(\overline{e_{h}}\right)^{3 / 2}}{\partial z}\right)-\frac{3 C_{\varepsilon}}{2 k^{2} C_{K}}\left(\overline{e_{h}}\right)^{3 / 2}=-\frac{3 U_{*}^{3}}{2 k^{2} C_{K}}$

which can be rewritten in:

$z^{2} \frac{\partial^{2}\left(\overline{e_{h}}\right)^{3 / 2}}{\partial z^{2}}+z \frac{\partial\left(\overline{e_{h}}\right)^{3 / 2}}{\partial z}-\frac{3 C_{\varepsilon}}{2 k^{2} C_{K}}\left(\overline{e_{h}}\right)^{3 / 2}=-\frac{3 U_{*}^{3}}{2 k^{2} C_{K}}$

The mathematical resolution of the previous equation leads to (see Appendix B):

$\frac{\overline{e_{h}}}{U_{*}^{2}}=\left(\frac{1}{C_{\varepsilon}}+a z^{n}+b z^{-n}\right)^{2 / 3}$

with $n=\frac{1}{k} \sqrt{\frac{3 C_{\varepsilon}}{2 C_{K}}} a$ and $b$, two constants.

Three conclusions can be drawn from the above expression of the horizontal variance profile:

1. in the close vicinity of the ground, the normalized kinetic energy is a variable of $z$;

2. many configurations of the normalized kinetic energy variation can be envisaged, including a constant ratio or a power of $z$, according to the degree of approximation;

3. when $z$ tends toward $0, f(z)=\overline{e_{h}} / U_{*}^{2}$ tends toward $\infty$; and when $z$ tends toward $\infty, f(z)$ tends towards $\infty$ too. This indicates that $f(z)$ is somewhat similar to the logarithm function;

When the contribution of $z$ is negligible, Eq. (16) becomes:

$\frac{\overline{e_{h}}}{U_{*}^{2}}=\left(\frac{1}{C_{\varepsilon}}\right)^{2 / 3}$
Relying on the values of $\overline{e_{h}} / U_{*}^{2}$ in Table 1 , it is possible to predict the values $C_{\varepsilon}$. These values are reported in Table 2 . Thus, it can be noticed that the values of $C_{\varepsilon}$ is of the same magnitude as the ones given by Stull (1988), i.e. 0.04 versus 0.09 .

It is not really convenient to treat Eq. (16) with the data collected from the WELSON experiment. It can be recalled that, in modeling the mean wind velocity profile, two kinds of relationships are proposed, i.e., the power model and the logarithmic one (cf. Appendix C). So, as for the mean wind velocity, we proposed a logarithmic relationship instead of the power relationship, since the first one will be more treatable with the available data.

In regard to Eq. (16), the profile of the wind velocity variance must have a logarithmic behaviour with a constant part. So the proposed relationship:

$\frac{\sigma_{h}^{2}}{U_{*}^{2}}=\alpha \ln (z)+b$

where $\sigma_{h}^{2}$ is the variance measured by the cup anemometer (see below for more specification on this parameter), $z$ the height and, $\alpha$ and $b$ two constants.

This relationship is a version of the one proposed by Carlotti (2001), which has been reported in Eq. (4).

\section{Experiments}

The data of this study derived from WELSONS (Wind Erosion and Losses of Soil Nutrients in semiarid Spain), which is a European research project devoted to the study of desertification and land degradation by wind erosion in the European Mediterranean area. The main objective of the project was to provide a better understanding of the impacts of climate and land-use changes on soil degradation by wind erosion for agricultural soils in the semiarid region of Northern Spain (Central Aragon, Spain, 1996-1998, see Fig. 1).

In a first paper, Frangi and Richard (2000) presented some results regarding the dynamics of the atmospheric surface layer (ASL) and the energy budget. After determining the main ASL parameters (friction velocity, roughness length, temperature scale, Monin-Obukhov length scale, etc.), it was pointed out that the two tillage methods induced differences in both dynamic characteristics and energy budget partitioning between the two plots. In a second paper, Yahaya et al. (2003) presented the influences of soil tillage treatment on some turbulent parameters, such as the Euler integral scales, the TKE dissipation rate, the spectral range of turbulence, the spectral energy containing-scale and the horizontal wind variance.

\subsection{Description of the experimental site}

For a complete description of the WELSONS experiment, with a detailed description of the site, one should refer to 


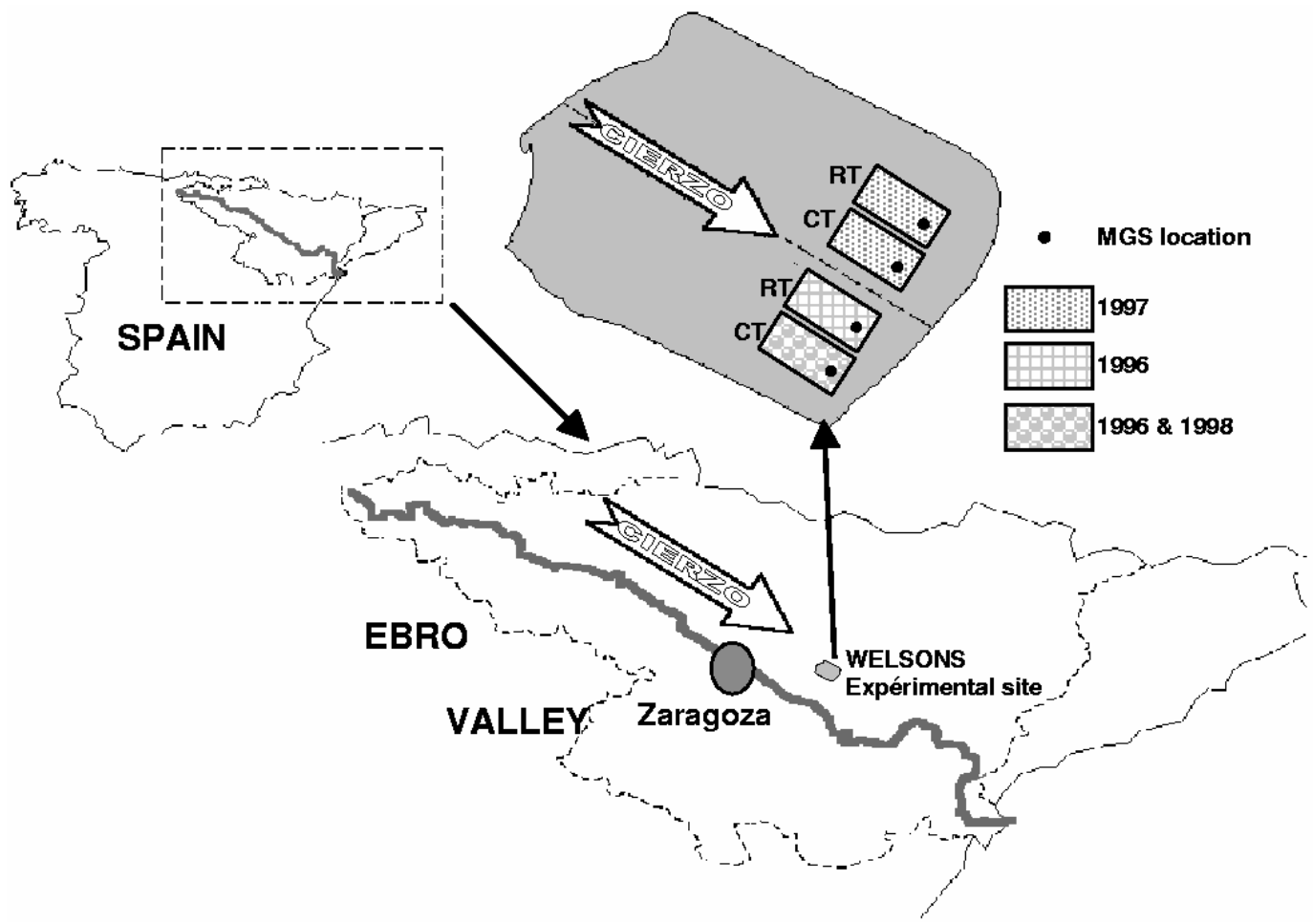

Fig. 1. General fetch of the WELSONS experimental site. One can notice the location of the conventional tillage (CT) and reduced tillage (RT) plots, changing according to years and the main wind direction following the Ebro valley (after Yahaya et al., 2003).

Table 2. Some values of $C_{\varepsilon}$ according to the values of the normalised kinetic energy.

\begin{tabular}{llccc}
\hline Atmospheric conditions & Authors & Specific conditions & $\frac{\sigma_{u}^{2}+\sigma_{v}^{2}}{U_{*}^{2}}$ & \multicolumn{2}{c}{$C_{\varepsilon}$} \\
\hline \multirow{2}{*}{ Neutral } & Stull (1988) & & 8.5 & 0.040 \\
Stable & Drobinski et al. (2004) & Flat terrain $(55 \mathrm{~m})$ & 8 to 9 & 0.044 \\
& Stull (1988) & & 8.5 & 0.037 \\
\hline
\end{tabular}

Frangi and Richard (2000) and Gomes et al. (2003). The climate of this Spanish region is strongly influenced by two winds, namely Cierzo and Borchono, which are bound to a specific orography. The Cierzo is the wind from the WNW direction, a very cold air stream in winter and cool in summer. In the opposite direction blows the Bochorno, with an ESE main direction, which appears when a pressure gradient exists between Mediterranean and Cantabrico Seas, with a low pressure field over the latter one.

The experimental field, located in an area called El Saso $\left(41^{\circ} 36^{\prime} \mathrm{N}, 0^{\circ} 32^{\prime} \mathrm{W}, 285 \mathrm{~m}\right.$ above mean sea level), $35 \mathrm{~km}$ away from Zaragoza in the Ebro Valley (Fig. 1), is oriented in the direction of the Cierzo prevailing wind (WNW). It remained untilled after a barley fallow rotation. Fields surrounding it, in the upwind edge, had very sparse vegetation. On both sides, at a distance of about $200 \mathrm{~m}$, there were wheat fields, with a vegetation canopy lower than $30 \mathrm{~cm}$. Some fallow fields of stubble separated these wheat fields from the experimental plots. The experimental field was divided into two adjacent plots $\left(140 \times 180 \mathrm{~m}^{2}\right.$, each $)$ for the application of two tillage treatments with a $20 \mathrm{~m}$ separation distance: conventional tillage (CT) and reduced tillage (RT). The CT treatment consisted of mouldboard ploughing, at a depth of 30$35 \mathrm{~cm}$, followed by the pass of a compacting roller to obtain a very flat ground: it constitutes the traditional practice in this area. The RT treatment, an alternative practice of conservation tillage (Lopez et al., 1996), consists of a unique pass of a chisel plough at a depth of about $15-20 \mathrm{~cm}$, giving a ground with furrows. In both cases, the tillages were done in the WNW direction. So the soil was bare with very different surface conditions during the whole experiment. 

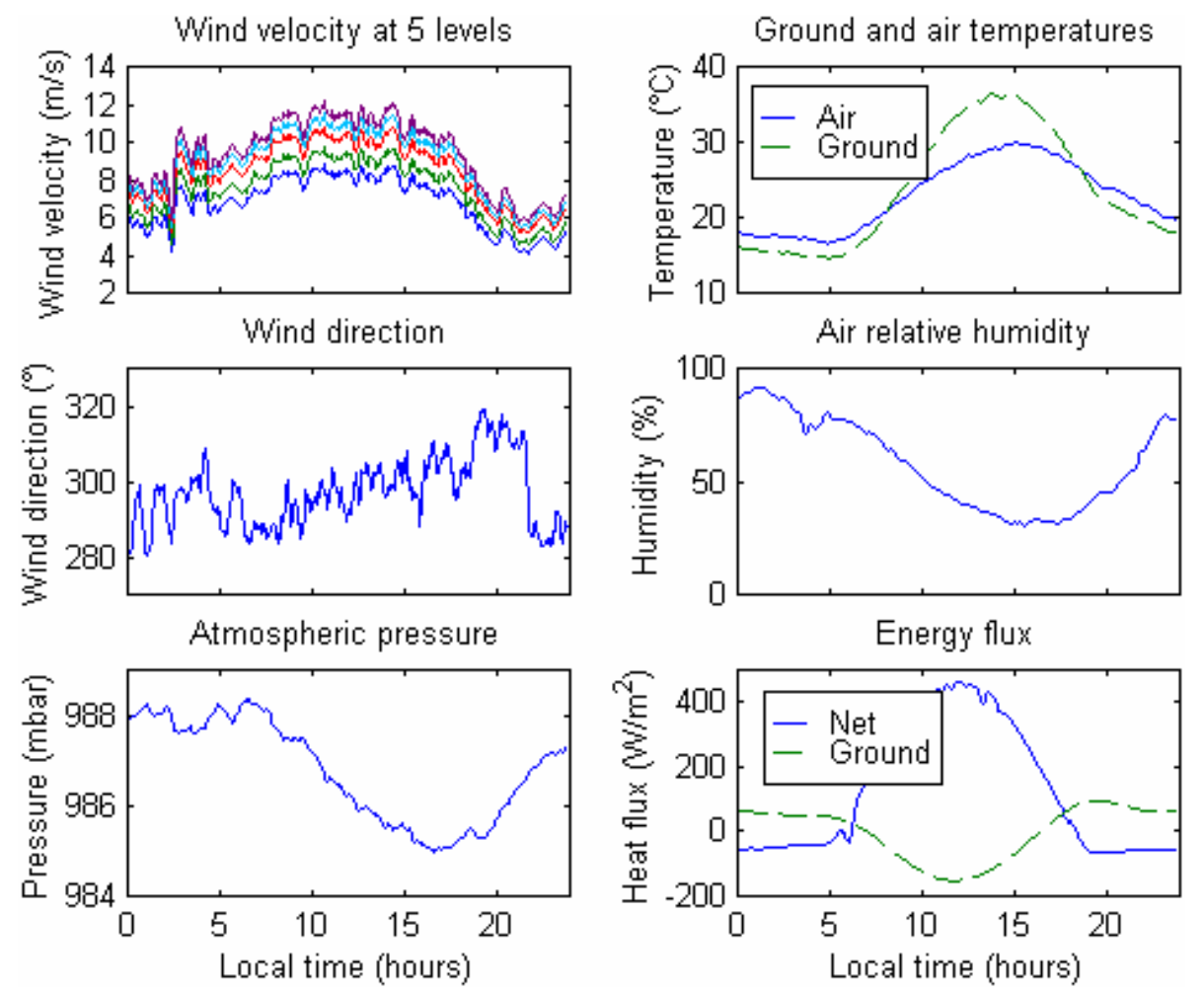

Fig. 2. Micro meteorological parameters measured during the experiment (Plot CT, 25 July 1997).

\subsection{Instrumentation}

Two micrometeorological ground station (MGS) systems (Frangi and Richard, 2000) have been developed and set up on the experimental field to study the dynamical characteristics of the soil surface and the energy budget partitioning in both plots. They were installed in the downwind edge of the field so as to monitor the fetch effects. The devices measure the energy budget parameters: wind speed and direction, air temperature and vapor pressure at two levels, net radiation and ground heat flux, soil and surface temperature, and atmospheric pressure. In addition, they record the wind profile every second, through a set of 5 cup anemometers installed along a $4 \mathrm{~m}$ height vertical mast (Frangi and Poullain, 1997). The five anemometer heights are 28, 53, 118, 203 and $402 \mathrm{~cm}$. We notice that the bottom height complies with the recommendation of Fritschen and Gay (1979), which stated that the anemometer height should be fivefold greater than the roughness length, $Z_{0}$ (i.e. 0.3 and $3 \mathrm{~mm}$, respectively, in plots CT and RT, see Table 7) The two MGS are synchronized. The 1997 WELSONS experiment was conducted from 29 June to 25 September.

The mean wind velocity at the highest level of plot CT is around $11 \mathrm{~m} \mathrm{~s}^{-1}$ during the daytime of 25 July 1997 and the turbulence intensity confined between $12 \%$ and $16 \%$ throughout the same day at the same level (cf. Fig. 2).

\subsection{Measurement uncertainty}

Some concerns could arise about the uncertainty of the measurement of the wind variance with cup anemometer. These concerns are of five orders: (i) the sampling error due to the fact that the sampling rate of the experiment is low; (ii) the spatial scales of the turbulence compared to the anemometer constant (iii) the instrumental error stemming from the inertial effects of the cup anemometer, (iv) the error due to the height variation and the ground proximity, and (v) the statistical atmospheric uncertainty.

First, let us consider the error related to the sampling rate. Then, the question is, from which eddy scale can a measurement be considered as having integrated the substance of the wind velocity variance? In a previous study, relating to the same experiment, Yahaya et al. (2003) showed that the length scales of the spectral peaks, range from $187 \mathrm{~m}$ (bottom level) to $522 \mathrm{~m}$ (upper level), on plot CT, and from $95 \mathrm{~m}$ to $450 \mathrm{~m}$, on plot RT. So, in the light of these results, we can affirm that the sampling cut-off scales represent about a tenth of the energy containing ones. In terms of energy, the ratio must be even lower. A complementary study carried out in an urban area, at University Diderot (Paris 7), with a three-dimensional sonic anemometer (Campbell CSAT3), shows variance losses of about $10 \%$ between samplings of 32 and $1 \mathrm{~Hz}$, for wind velocity around $4 \mathrm{~m} \mathrm{~s}^{-1}$ with turbulence intensity of about $40 \%$ (Yahaya, 2004). In addition, 
this accordance between experimental data and the von Karman modelling spectra, notably in the upper frequency part, reinforces credit to the quality of the measurements (cf. Yahaya et al., 2003).

On the one hand, a previous study (cf. Yahaya et al., 2003) focused on the relationship between the turbulence structure and the terrain surface. The study considered the fourth levels of measurements of the two plots. The spectral gap, which separates the turbulent flow from the influences of the mean flow has been located. The location of the gap allowed determining the best sample's time interval separating the two scales of the flow. On the other hand, the study allowed verification that, the turbulence scales depend, not only on the height level, but also on the terrain roughness.

The instrumental error, which stems from the inertial effects of the cup anemometer, has been deeply studied in Yahaya and Frangi (2004). Given the anemometers' distance constants $(L \approx 1.3 \pm 0.35 \mathrm{~m})$ and the mean wind velocity (cf. Fig. 2), the variance reduction due to the inertial effects was estimated at a small percentage. In this regard, Kristensen (1998) states that the overspeeding phenomenon of the cup anemometer is only relevant when the mean wind speed is concerned. Otherwise, it is possible to use a cup anemometer for measuring the fluctuating, streamwise velocity component with a spatial resolution that corresponds to almost that of a sonic anemometer.

Three phenomena could affect the measurement of the wind variance from one height to another. The first one is the proximity of the ground which could hinder the device efficiency. This question has already been dealt with in the previous section. The second one is the variation of the mean wind with height. As it has been reported, the mean distance constant of the studied anemometers is $L=1.3 \mathrm{~m}$. The maximum accessible frequency, corresponding to the cutoff frequency at the amplitude attenuation coefficient $\alpha=\sqrt{2} / 2$ (cf. Guyot, 1997), is given by:

$$
f_{c o}=\frac{U}{2 \pi L}
$$

where $U$ is the mean wind velocity. Given that the mean wind speeds, at the bottom levels, during the study period (25 July 1997; 07:00-17:00 LT), are 8.0 and $6.7 \mathrm{~m} \mathrm{~s}^{-1}$ on plots $\mathrm{CT}$ and RT, thus the maximum accessible frequencies are 0.9 and $0.8 \mathrm{~Hz}$. These frequencies are greater than the sampling Nyquist frequency of the experiment (i.e. $0.5 \mathrm{~Hz}$ ). For the higher levels, where the mean wind speeds are higher, the anemometers accuracy is then better. The third phenomenon is linked to the variation of the embraced spectrum, which also changes with heights. The spectral cut toward higher wave numbers with increasing altitude makes the spectral range wider for lower levels, i.e.:

$\kappa_{s 1}=\frac{2 \pi}{T_{S} U}=\frac{2 \pi k}{U_{*} T_{S} \ln \left(\frac{z_{1}}{Z_{0}}\right)}>\kappa_{S}=\frac{2 \pi k}{U_{*} T_{S} \ln \left(\frac{z_{5}}{Z_{0}}\right)}$ where $z_{1}$ and $z_{5}$ are heights at levels 1 and $5, \kappa_{s}$ and $T_{s}$ are the sampling wave number and period, $U_{*}$ the friction velocity, $k$ the von Karman constant and $Z_{0}$ the roughness length. This has the effect of increasing the lower altitude variance whereas the aim of this study is to show that the variance decreases with decreasing altitude. So this phenomenon will have no effect on the conclusion of this paper.

Even if the cutoff frequency, $f_{c o}$, of the used anemometer is about $2 \mathrm{~Hz}$ in temporal mode, its upper frequency limit attains $12 \mathrm{~Hz}$ as it is reported in Yahaya and Frangi (2004). In fact, the sampling rate of $1 \mathrm{~Hz}$ is an average of the higher frequencies measurement. The effective frequency measurement of the anemometer, as well as the upper frequency limit, are determined by the mean wind velocity.

The relative statistical atmospheric uncertainty of the second moment, for a Gaussian distribution with zero mean, is given by Lumley and Panofsky (1964):

$\operatorname{Err}=2 \sqrt{\frac{T_{u}}{T_{s}}}$

where Err is the relative uncertainty, $T_{u}$ the Eulerian time integral scale and $T_{s}$ the sampling time interval. The time integral scale, which is given by the integral of the correlation function, $\rho(t)$, between 0 and $\infty$, represents the time scale within which the considered turbulent parameter remains auto-correlated. Table 3 gives the values of the Eulerian time integral scale $T_{u}$, stemming from a previous study relating to the same experiment (Yahaya et al., 2003). With these values, we determined the expected relative uncertainty on the variance measurement (second moment of the wind velocity), under the assumption of normal distribution, for an averaging interval of $14 \mathrm{~min}$ (see also Table 3). We notice that the parameter varies from $15 \%$ to $20 \%$ according to the considered height and the experimental site. It is possible to bring these figures to about $10 \%$ by increasing the average interval, for example to $30 \mathrm{~min}$. But this conceivable operation is unlikely to change the results of this study.

\section{Results}

The wind data logged during the WELSONS experiment concern the bottom part of the ASL since the lowest anemometer is located at $0.25 \mathrm{~m}$ from the ground while the highest one is at $4 \mathrm{~m}$ (thus covering a height scale ratio of 16). This particularity of the experiment, due to its specific objectives, is expected to produce different results from common micro-meteorological experiments, which were carried out in the upper eddy surface layer to the shear surface layer (cf. Drobinski et al., 2004, for the subdivision of the surface layer).

The WELSONS experiment somewhat marks off from the cases reported in Sect. 2 , since it took place in the very vicinity of the ground. At these heights, the ground effects become important and thus the roughness length becomes a 
Table 3. Statistical atmospheric uncertainty of the second moment (variance) for a Gaussian probability distribution. The integral scales stem from a previous study relating to the same experiment (Yahaya et al., 2003).

\begin{tabular}{|c|c|c|c|c|c|c|c|}
\hline \multirow[b]{2}{*}{ Height (m) } & \multicolumn{2}{|c|}{$\begin{array}{c}\text { Plot CT } \\
\text { Integral scales, Euler }\end{array}$} & \multirow{2}{*}{$\begin{array}{c}\text { Relative } \\
\text { uncertainty }\end{array}$} & \multirow[b]{2}{*}{ Height (m) } & \multicolumn{2}{|c|}{ Plot RT } & \multirow{2}{*}{$\begin{array}{c}\text { Relative } \\
\text { uncertainty }\end{array}$} \\
\hline & Time (s) & Length (m) & & & Time (s) & Length (m) & \\
\hline 0.28 & 5.48 & 43.7 & $16 \%$ & 0.29 & 4.26 & 28.0 & $14 \%$ \\
\hline 0.53 & 5.85 & 51.6 & $17 \%$ & 0.54 & 4.52 & 34.1 & $15 \%$ \\
\hline 1.18 & 6.72 & 66.1 & $18 \%$ & 1.19 & 5.08 & 42.9 & $16 \%$ \\
\hline 2.03 & 7.21 & 75.3 & $19 \%$ & 2.03 & 5.74 & 54.1 & $17 \%$ \\
\hline 4.04 & 8.17 & 90.0 & $20 \%$ & 4.03 & 7.19 & 76.9 & $19 \%$ \\
\hline
\end{tabular}
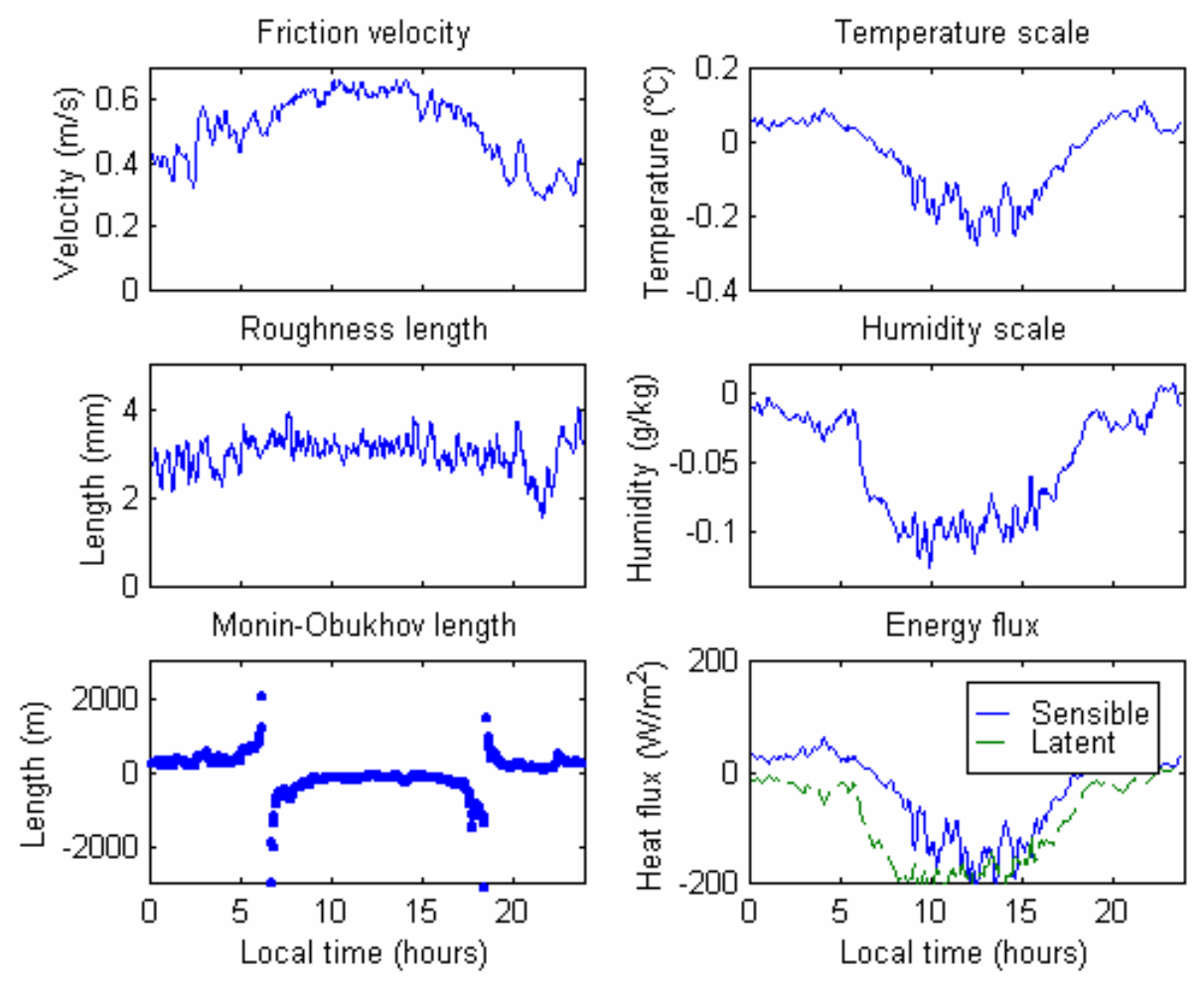

Fig. 3. Dynamic parameters of that ASL (Plot CT, 25 July 1997).

relevant parameter, as it is in the case reported by Solari (1987). In addition, Hedde and Durand (1994) and Pahlow et al. (2001) reported that, in some circumstances, the variances of the horizontal wind components depend on the height. Besides any thermal stability considerations, the layer studied in the WELSONS experiment is rather a dynamic one because the considered heights are negligible compared to the Monin-Obukhov length (Fig. 3) and the friction velocity is high (respectively 0.4 and $0.5 \mathrm{~m} \mathrm{~s}^{-1}$ in the two plots). These conditions of the occurrence of the dynamic layer were specified by De Moor (1983).

Since the study does not include the vertical wind component, the turbulent wind fluctuations were linearly detrended in order to remove the mean flow influences. The variances are calculated over 14 min time intervals to match with the friction velocity and the roughness length data reported by Frangi and Richard (2000).

\subsection{Modelling the profile of the horizontal wind vari- ance}

As demonstrated in Sect. 3, Fig. 4 shows that, in the specific conditions of this experiment, the wind horizontal variance varies with the height. In this figure, as well as in Fig. 5, independently to the wind speed values and to the local time (thus to the stability parameter), there is a reduction of the horizontal wind variance as the anemometer height decreases. One can notice that the variance reduction is an 


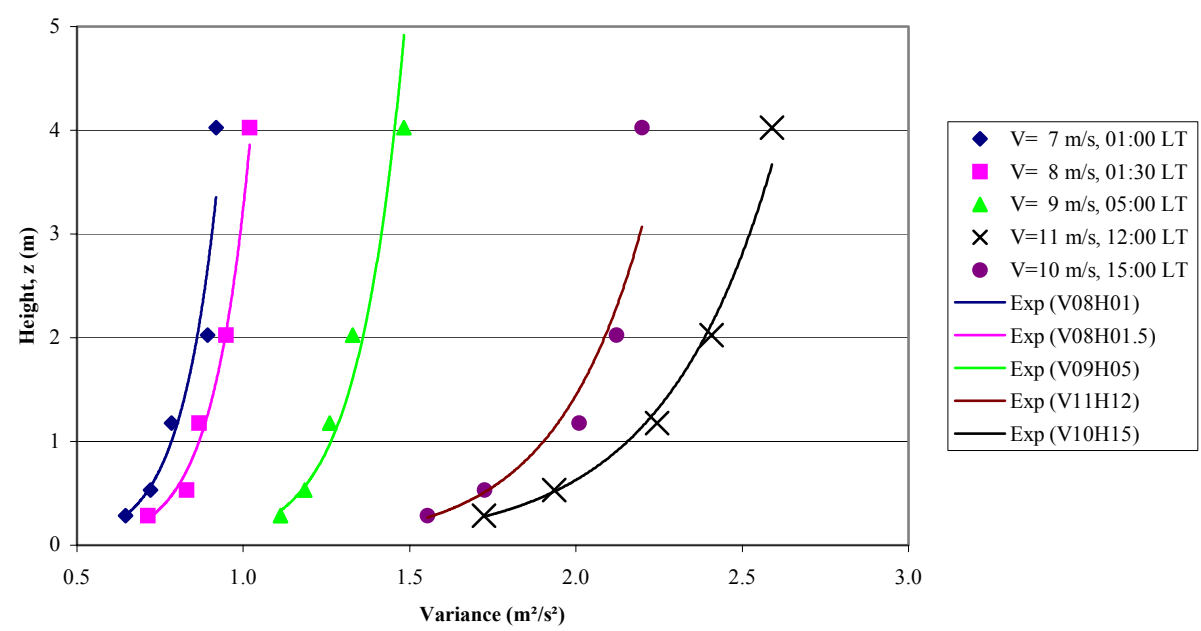

Fig. 4. Variation of the horizontal wind variance with height (Plot CT, 25 July 1997).

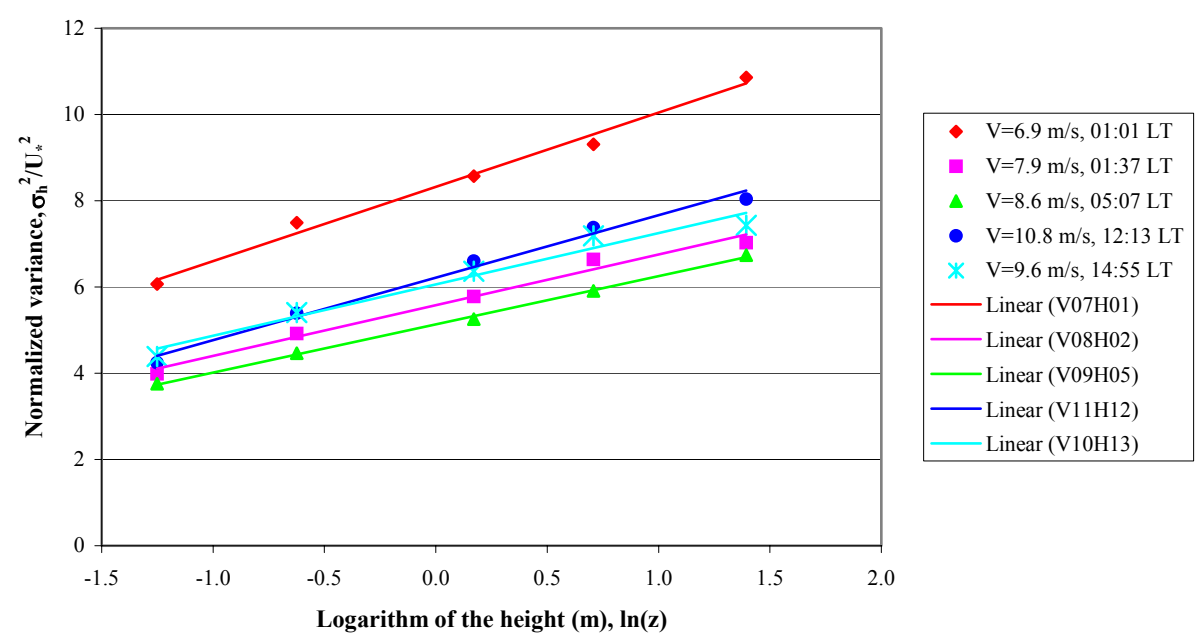

Fig. 5. Variance normalized by the square of the friction velocity as a function of height logarithm (Plot RT, 25 July 1997).

increasing function of the wind speed. Although the plots include some night data, however, the study concerns only the period 07:00-17:00 LT, where the mean wind is roughly stationary.

This reduction of the horizontal wind variance has been reported by Drobinski et al. (2004). Thus, they showed that, in the quasi-neutral flow, the normalised horizontal variances increase between the ground and $0.015 Z_{i}$ (i.e., about $10 \mathrm{~m}$ ), where they reach a maximum, then decrease with height.

Recalling Eq. (18), it can be noticed, in Fig. 5 and Table 4, that the variance, normalised by the square of the friction velocity, is a linear function of the logarithm of the height. The data of this analysis, notably the values of the friction velocity, stem from the MW method where the results have been previously published (Frangi and Richard, 2000). One can also notice in Table 4 that the linear correlation coefficient $\mathrm{R}^{2}$ is higher than 0.9 in $95 \%$ of the 475 cases at plot CT and in $97 \%$ of cases at plot RT.
This confirms the validity of the previous approximations and of the model stemming from the RDT and proposed by Carlotti (2001). However, it can be noticed that, on the contrary to the Carlotti's relationship, Fig. 4 shows that the variance is a growing function of $z$. This is in accordance with the prediction of Drobinski et al. (2004).

As the variance measured by cup anemometers, $\sigma_{h}^{2}$, is the sum of the longitudinal and transversal variance, from Eq. (18), we have:

$$
\frac{\sigma_{h}^{2}}{U_{*}^{2}}=\frac{\overline{u^{\prime 2}}+\overline{v^{\prime 2}}}{U_{*}^{2}}=\alpha \ln \left(\frac{z}{Z_{0}}\right)-\delta
$$

Combining Eqs. (18) and (22), we have a relationship between $b$ and $-\ln \left(Z_{0}\right)$ in the form of:

$b=-\left(\delta+\alpha \ln \left(Z_{0}\right)\right)$

It can be noticed, in Table 4 , that $\alpha$ is roughly constant in the two plots while the roughness length increases tenfold and the friction velocity by $25 \%$ from plot CT to plot RT. 
Table 4. Linear regression parameters of the function $\sigma_{h}^{2} / U_{*}^{2}=f(\ln (z))=\alpha \ln (z)+b$, using the values of $U_{*}$ stemming from the MW method.

\begin{tabular}{|c|c|c|c|c|c|c|}
\hline & \multirow{2}{*}{$R^{2}>0.90($ total of cases $=475)$} & \multirow{2}{*}{\multicolumn{2}{|c|}{$\begin{array}{l}\text { Slope, } \alpha \\
\text { Variation coefficient }\end{array}$}} & \multicolumn{2}{|r|}{ Intercept, $b$} & \multirow{2}{*}{$-\ln \left(Z_{0}\right)$} \\
\hline & & & & Average & Variation coefficient & \\
\hline Plot CT & $95 \%$ & 1.160 & $32 \%$ & 8.074 & $15 \%$ & 8.11 \\
\hline Plot RT & $97 \%$ & 1.156 & $26 \%$ & 5.311 & $17 \%$ & 5.81 \\
\hline
\end{tabular}

Table 5. Values of $\alpha$ and correlation between " $b$ " and $Z_{0}$, according to the determination methods of $U_{*}$ and $Z_{0}$.

\begin{tabular}{|c|c|c|c|c|}
\hline \multirow[t]{2}{*}{ Considered plot } & \multicolumn{2}{|c|}{$\begin{array}{l}\text { Constant } \alpha \text { according to the } \\
\text { determination method of } U_{*} \text { : }\end{array}$} & \multicolumn{2}{|c|}{$\begin{array}{c}\text { Correlation between } b \text { and }-\ln \left(Z_{0}\right) \text { according } \\
\text { to the determination method of } Z_{0}:\end{array}$} \\
\hline & MW Method & Simple logarithmic method & MW method & Simple logarithmic method \\
\hline Plot CT & 1.160 & 1.22 & 0.21 & 0.36 \\
\hline Plot RT & 1.156 & 1.18 & 0.56 & 0.46 \\
\hline
\end{tabular}

Table 6. Experimental values of the remainder, $\delta$.

\begin{tabular}{lccccc}
\hline $\begin{array}{l}\text { Considered } \\
\text { plot }\end{array}$ & Level 1 & Level 2 & Level 3 & Level 4 & Level 5 \\
\hline Plot CT & 1.45 & 1.35 & 1.51 & 1.36 & 1.44 \\
Plot RT & 1.41 & 1.25 & 1.41 & 1.29 & 1.38 \\
\hline
\end{tabular}

Besides the accuracy of the anemometers, the experimental value of $\alpha$ also depends on the determination method of $U_{*}$ and $Z_{0}$. Thus, Table 5 presents the values of $\alpha$ and of the correlation between " $b$ " and $Z_{0}$ (cf. Eq. 23) according to the methods used for the determination of $U_{*}$ and $Z_{0}$. These parameters have been calculated through the MW method, introduced by Frangi and Richard (2000), which takes into account the energy budget parameters, and through the logarithmic model of the mean wind velocity, neglecting thermal effects (cf. Appendix D). Thus, we state that $\alpha$ varies by less than $3 \%$, between the two plots, no matter the used method, while the correlation between $b$ and $-\ln \left(Z_{0}\right)$ is higher with the logarithmic model method. This correlation has been evaluated through the 475 case studies with the imbedded Microsoft Excel function of the working computer.

In Table 6, it can be noticed that the values of the remainder, $\delta$, of Eq. (22), are constant and do not depend on the experimental plots and neither on the anemometer heights. In addition, a strong correlation has been noticed between " $b$ " and the roughness length, particularly when the latter is determined through the mean velocity logarithmic model, neglecting thermal effects. Figure 6 suggests that the slope of the linear regression between " $b$ " and $-\ln \left(Z_{0}\right)$ is very close to $1 / 2$, in the two plots. However, the vertical intercept of the regression is somewhat different from zero.

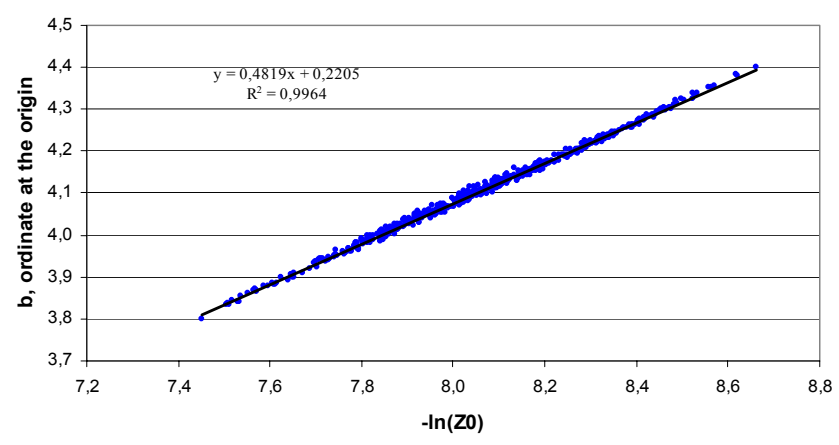

Fig. 6. Linear regression between the ratio $b^{\prime} / a^{\prime}$ and the opposite of the logarithm of the roughness length.

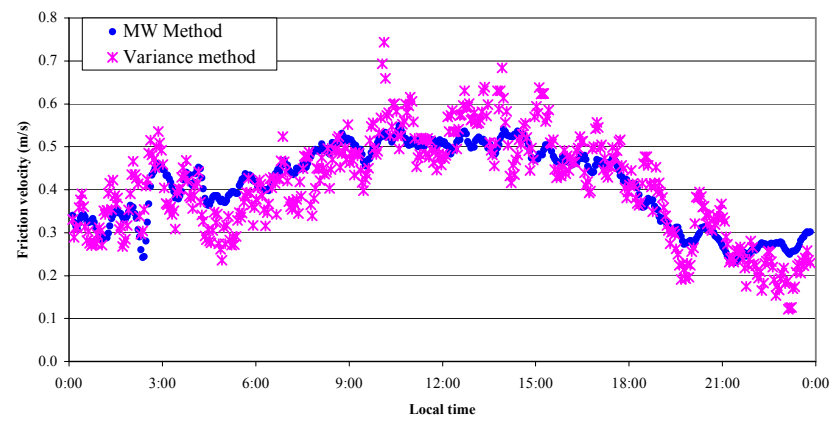

Fig. 7a. Friction velocity. Comparison between the statistical method MW and the variance method (Plot CT, 25 July 1997). 


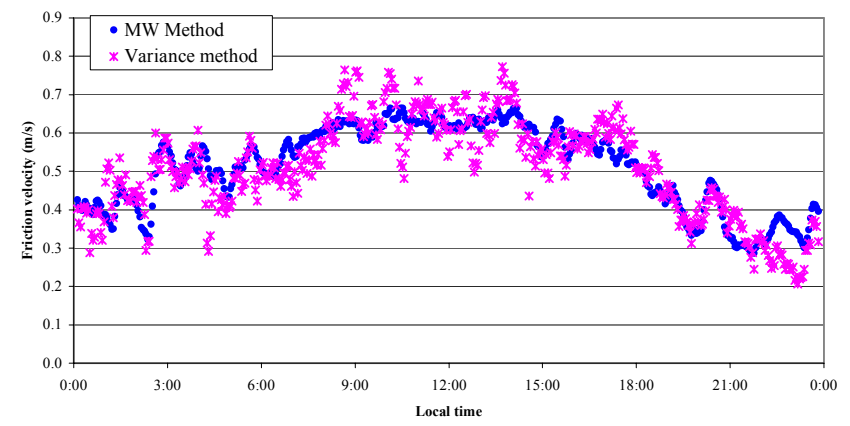

Fig. 7b. Friction velocity. Comparison between the statistical method MW and the variance method (Plot RT, 25 July 1997).

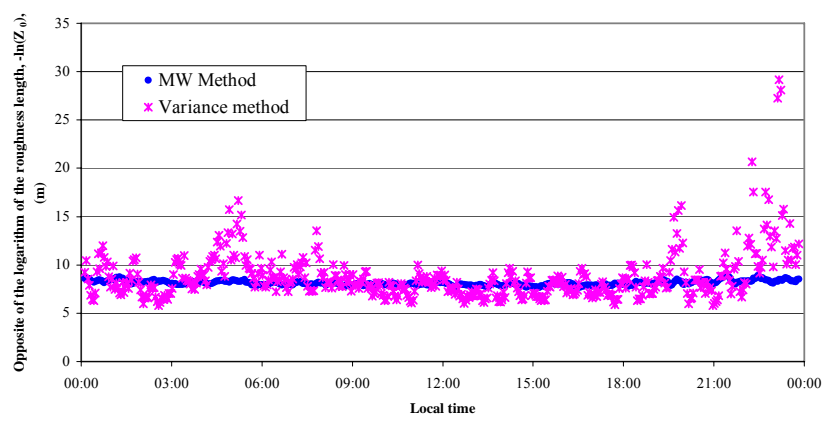

Fig. 8a. Roughness length. Comparison between the statistical method MW and the variance method (Plot CT, 25 July 1997).

\subsection{Determination of the friction velocity and the roughness length from the profile of the horizontal wind variance}

After adopting the experimental value of the previously defined constants $\alpha$ and $\delta$ (cf. Tables 5 and 6), it is proposed to determine, exclusively from Eq. (22), the friction velocity and the roughness length, in order to show that the equation can be used in a way or a reverse. For this purpose, this equation is rewritten in the form:

$\sigma_{h}^{2}=\alpha U_{*}^{2} \ln (z)-U_{*}^{2}\left(\alpha \ln \left(Z_{0}\right)+\delta\right)$

This can be rewritten as:

$\sigma_{h}^{2}=a_{1} \ln (z)+b_{1}$

with $a_{1}=\alpha U_{*}^{2}$ and $-\ln \left(Z_{0}\right)=\frac{b_{1}}{a_{1}}+\frac{\delta}{\alpha}$.

The friction velocity, $U_{*}$, and the roughness length, $Z_{0}$, may be determined, through linear regression, from Eq. (23b), by using the measurements of the five anemometer levels.

Figures $7 \mathrm{a}, \mathrm{b}, 8 \mathrm{a}$ and $\mathrm{b}$ compare the values of the friction velocity and the roughness length stemming from the variance Eq. (23b) and those determined by Frangi and Richard (2000), through the statistical method MW. Table 7 completes the comparison between the two data sets by presenting the mean values and the correlation coefficients. Thus,

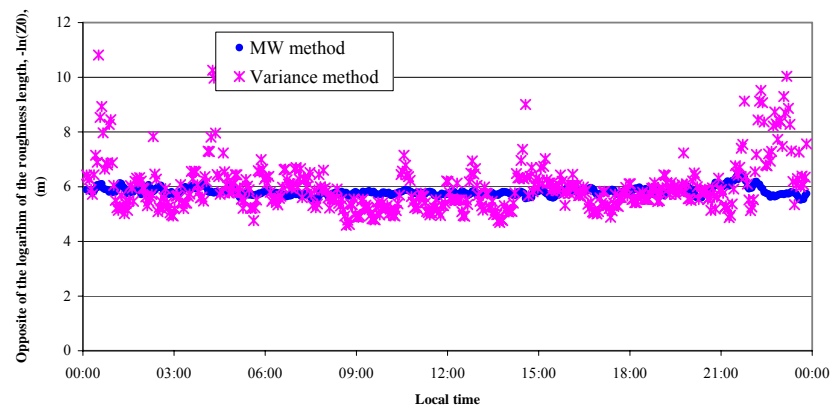

Fig. 8b. Roughness length. Comparison between the statistical method MW and the variance method (Plot RT, 25 July 1997).

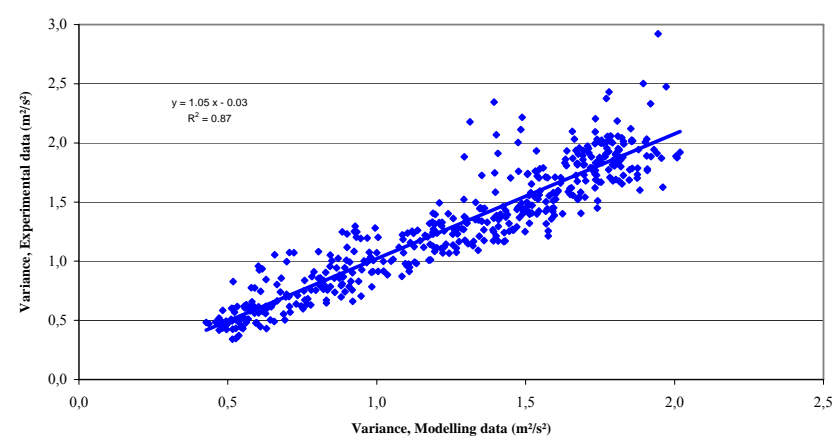

Fig. 9. Variance. Comparison between the experimental and the modeled data, for $\alpha=1.20$ and $\delta=1.36$ (Plot RT, Level 2).

a good agreement is noticed between the two methods with a correlation of about 0.9 for the friction velocity. For the roughness length, which varies slightly, the correlation coefficients are somewhat lower.

\subsection{Generation of the horizontal wind variance from the friction velocity and the roughness length}

From Eq. (23a), and after adopting the experimental value of $\alpha$ and $\delta$ (cf. Tables 5 and 6), we can generate the variance for every anemometer height. It is to be specified that $\alpha$ and $\beta$ have been determined through the combination of five measurement levels. Now, the same constants will be used for each given single level. Figure 9 presents a comparison between the experimental and the modeled variance data (cf. Eq. 21). The friction velocity and the roughness length values were calculated through the logarithmic profile of the mean wind velocity (neglecting thermal effects). Table 8 reports the parameters of the linear regression between the modelling and the experimental data, for the five anemometer heights of each plot. It may be noticed that the linear correlation coefficient, the slope and the vertical intercept indicate good agreement between the two data sets. Comparable results were also obtained with the friction velocity and the roughness length calculated through the statistical method MW. 
Table 7. Comparison parameters between the values of the friction velocity and the roughness stemming from the statistical method MW and the variance method, for $\alpha=1.16$ and $\delta=1.4$ (25 July 1997, over $24 \mathrm{~h}$ ).

\begin{tabular}{llcc}
\hline & & Plot CT & Plot RT \\
\hline \multirow{3}{*}{ Mean values of the friction velocity, $U_{*}$} & Statistical method MW & 0.41 & 0.51 \\
& Variance method & 0.41 & 0.51 \\
& Correlation between the two data sets & 0.86 & 0.87 \\
\hline \multirow{3}{*}{ Mean values of the logarithm of the roughness length } & Statistical method MW & 8.14 & 5.82 \\
& Variance method & 8.79 & 5.98 \\
& Correlation between the two data sets & 0.71 & 0.35 \\
\hline
\end{tabular}

Table 8. Horizontal wind variance. Linear regression parameters between the experimental and the modelling data, $\alpha=1.20$ and $\delta=1.36$.

\begin{tabular}{|c|c|c|c|c|c|}
\hline & & Linear correlation coefficient $\left(R^{2}\right)$ & Slope $(a)$ & Vertical intercept $(b)$ & Ratio of $|b|$ to mean variance \\
\hline \multirow{5}{*}{ Plot CT } & Level 1 & 0.88 & 1.02 & -0.02 & $2 \%$ \\
\hline & Level 2 & 0.87 & 1.06 & -0.04 & $3 \%$ \\
\hline & Level 3 & 0.86 & 1.07 & -0.09 & $6 \%$ \\
\hline & Level 4 & 0.84 & 1.07 & -0.07 & $5 \%$ \\
\hline & Level 5 & 0.85 & 1.13 & -0.18 & $10 \%$ \\
\hline \multirow{5}{*}{ Plot RT } & Level 1 & 0.88 & 1.09 & -0.01 & $1 \%$ \\
\hline & Level 2 & 0.87 & 1.05 & -0.03 & $2 \%$ \\
\hline & Level 3 & 0.84 & 1.01 & -0.08 & $6 \%$ \\
\hline & Level 4 & 0.83 & 0.97 & -0.06 & $4 \%$ \\
\hline & Level 5 & 0.83 & 0.98 & -0.16 & $9 \%$ \\
\hline
\end{tabular}

It appears that the studied model gives values of the horizontal wind variance in good agreement with experimental data. Thus, it can be used for more accurate modelling of parameters involving the variance or the standard deviation of the horizontal wind (e.g. wind velocity peak or gust factors, rate of TKE transport, etc.)

\section{Conclusion}

This study showed that, in the vicinity of the ground, the variance of the horizontal wind varies logarithmically with height. The parameters of the logarithmic function include the friction velocity and the roughness length scale. Thus, the study leads to a formulation of the similarity universal function of the horizontal wind variance, near the ground, i.e.:

$\frac{\sigma_{h}^{2}}{U_{*}^{2}}=f_{\sigma_{h}}\left(\frac{z}{Z_{0}}\right)=\alpha \ln \left(\frac{z}{Z_{0}}\right)-\delta$

where $\alpha$ and $\delta$ are two constants. As a matter of fact, the values of $\alpha$ varies by less than 3\%, between the plots, while the roughness length increases tenfold and the friction velocity by $25 \%$ from plot CT to plot RT (cf. Table 4 ). The values of $\delta$ reveal to be independent from the experimental plots and the anemometer heights (cf. Table 6).

The model, introduced by this study, allowed us to determine the friction velocity and the roughness length in good accordance with data provided by other methods, such as the MW method or the mean velocity logarithmic profile method (cf. Table 7).

These results could be used for accurate calculations of the wind velocity standard deviation and variance in models involving these two parameters (e.g., wind velocity peak or gust factors). They could also be used in the evaluation the TKE transport rate near the ground.

Further studies are necessary to investigate the limits of the model, the validity of which is presently limited to a few meters, and under the limiting assumptions made herein. Future studies will also have to confirm the values of constants $\alpha$ and $\delta$. 
Abbreviations and acronyms

$\begin{array}{ll}\text { ABL } & \text { Atmospheric Boundary Layer } \\ \text { ASL } & \text { Atmospheric Surface Layer } \\ \text { CT } & \text { Conventional Tillage } \\ \text { ESE } & \text { East-South-East } \\ \text { ESL } & \text { Eddy Surface Layer } \\ \text { MGS } & \begin{array}{l}\text { Micrometeorological Ground Station } \\ \text { Statistical method of the computation } \\ \text { MW }\end{array} \\ & \begin{array}{l}\text { of the ASL parameters, introduced by } \\ \text { Frangi and Richard (2000) }\end{array} \\ \text { RDT } & \text { Rapid Distortion Theory } \\ \text { RT } & \text { Reduced Tillage } \\ \text { TKE } & \text { Turbulent kinetic energy } \\ \text { WELSONS } & \begin{array}{l}\text { Wind Erosion and Losses of Soil Nu- } \\ \text { trients in semiarid Spain }\end{array} \\ \text { WNW } & \text { West-North-West }\end{array}$

\section{List of symbols}

a Constant, generally slopes of linear regressions

$b \quad$ Constant, generally the vertical intercept of linear regressions

C Constant

$c_{i j} \quad$ Constant of order one

$C_{K} \quad$ Constant relating to the parameterization of the eddy diffusivity

$C_{\varepsilon} \quad$ Constant relating to the equation of the TKE dissipation rate

$\bar{e} \quad$ Mean kinetic energy

$E_{11} \quad$ longitudinal velocity spectrum

Err Relative uncertainty

$f_{\max }$ Maximum frequency accessible by a cup anemometer

$f_{\sigma_{h}} \quad$ Universal function related to the horizontal wind variance

$k \quad$ Von Karman constant

$K \quad$ Eddy diffusivity

$K_{u} \quad$ Eddy viscosity relating to the momentum

$l \quad$ TKE dissipation length scale

$L \quad$ TKE dissipation length scale

$L \quad$ Monin-Obukhov length, Distance constant of the cup anemometer

$T \quad$ Averaging time interval

$T_{s} \quad$ Time, sampling rate

$T_{u} \quad$ Time integral scale

$u \quad$ Longitudinal wind velocity

$U \quad$ Mean wind velocity

$U_{*} \quad$ Friction velocity

$v \quad$ Transversal wind velocity

$w \quad$ Vertical wind velocity

$z \quad$ Height
$Z_{0} \quad$ Roughness length

$Z_{i} \quad$ Daytime atmospheric boundary layer depth

$Z_{h} \quad$ Atmospheric boundary layer depth

$\alpha \quad$ Constant, slope of variance profile

$\beta_{13} \quad$ Unknown shear parameter

$\beta_{u} \quad$ Constant ratio between the longitudinal wind variance and the square of the friction velocity

$\gamma \quad$ Proportionality "constant" between the eddy viscosity and the eddy diffusivity

$\delta \quad$ Constant relating to the universal function

$\varepsilon \quad$ TKE dissipation rate

$\zeta \quad$ Stability parameter

$\kappa \quad$ Wave number

$\Lambda \quad$ Length scale characterising the lower limit of the -1 range in the spectrum

$\sigma \quad$ Standard deviation

$\sigma_{h}^{2} \quad$ Horizontal wind variance measured by cup anemometers

$\sigma_{u} \quad$ Longitudinal wind standard deviation

\section{Appendix A}

The Navier-Stockes equations of the turbulent flow for each wind component, using the Einstein notations (with summation on $j$ ), are:

$$
\begin{aligned}
\frac{\partial \overline{u_{i}^{\prime 2}}}{\partial t}+\overline{u_{j}} \frac{\partial \overline{u_{i}^{\prime 2}}}{\partial x_{j}}= & 2 \delta_{i 3} g \frac{\overline{u_{i}^{\prime} \theta_{v}^{\prime}}}{\overline{\theta_{v}}}-2 \overline{u_{i}^{\prime} u_{j}^{\prime}} \frac{\partial \overline{u_{i}}}{\partial x_{j}}-\frac{\partial\left(\overline{u_{j}^{\prime} u_{i}^{\prime 2}}\right)}{\partial x_{j}} \\
& -\frac{2}{\bar{\rho}} \frac{\partial\left(\overline{u_{i}^{\prime} p^{\prime}}\right)}{\partial x_{i}}-2 \varepsilon_{i}
\end{aligned}
$$

with $\varepsilon_{i}=v \overline{\left(\frac{\partial u_{i}^{\prime}}{\partial x_{j}}\right)^{2}}$.

By choosing the $x$-axis aligned with the mean wind ( $\overrightarrow{o x}=$ mean wind vector) and the $z$-axis the upward vertical ( $\overrightarrow{o z}=$ upward vertical), then we have: $\bar{V}=0$ et $\bar{W}=0$. For a steady flow, the previous equations become for each component:

$$
\begin{aligned}
\bar{u} \frac{\partial \overline{u^{\prime 2}}}{\partial x}= & -2\left(\overline{u^{\prime 2}} \frac{\partial \bar{u}}{\partial x}+\overline{u^{\prime} v^{\prime}} \frac{\partial \bar{u}}{\partial y}+\overline{u^{\prime} w^{\prime}} \frac{\partial \bar{u}}{\partial z}\right) \\
& -\left(\frac{\partial \overline{u^{\prime 3}}}{\partial x}+\frac{\partial \overline{v^{\prime} u^{\prime 2}}}{\partial y}+\frac{\partial \overline{w^{\prime} u^{\prime 2}}}{\partial z}\right)-\frac{2}{\bar{\rho}} \frac{\partial \overline{u^{\prime} p^{\prime}}}{\partial x}-2 \varepsilon_{1}( \\
\bar{u} \frac{\partial \overline{v^{\prime 2}}}{\partial x}=- & \left(\frac{\partial \overline{u^{\prime} v^{\prime 2}}}{\partial x}+\frac{\partial \overline{v^{\prime 3}}}{\partial y}+\frac{\partial \overline{w^{\prime} v^{\prime 2}}}{\partial z}\right)-\frac{2}{\bar{\rho}} \frac{\partial \overline{v^{\prime} p^{\prime}}}{\partial y}-2 \varepsilon_{2} \\
\bar{u} \frac{\partial \overline{w^{\prime 2}}}{\partial x}= & 2 g \frac{\overline{w^{\prime} \theta_{v}^{\prime}}}{\overline{\theta_{v}}}-\left(\frac{\partial \overline{u^{\prime} w^{\prime 2}}}{\partial x}+\frac{\partial \overline{v^{\prime} w^{\prime 2}}}{\partial y}+\frac{\partial \overline{w^{\prime 3}}}{\partial z}\right) \\
& -\frac{2}{\bar{\rho}} \frac{\partial \overline{w^{\prime} p^{\prime}}}{\partial z}-2 \varepsilon_{3}
\end{aligned}
$$


Summing Eqs. (A2a) and (A2b) yields:

$$
\begin{aligned}
\bar{u} \frac{\partial\left(\overline{u^{\prime 2}}+\overline{v^{\prime 2}}\right)}{\partial x}= & -2\left(\overline{u^{\prime 2}} \frac{\partial \bar{u}}{\partial x}+\overline{u^{\prime} v^{\prime}} \frac{\partial \bar{u}}{\partial y}+\overline{u^{\prime} w^{\prime}} \frac{\partial \bar{u}}{\partial z}\right) \\
& -\left(\frac{\partial \overline{u^{\prime 3}}}{\partial x}+\frac{\partial \overline{v^{\prime} u^{\prime 2}}}{\partial y}+\frac{\partial \overline{w^{\prime} u^{\prime 2}}}{\partial z}\right)+ \\
& -\left(\frac{\partial \overline{u^{\prime} v^{\prime 2}}}{\partial x}+\frac{\partial \overline{v^{\prime 3}}}{\partial y}+\frac{\partial \overline{w^{\prime} v^{\prime 2}}}{\partial z}\right) \\
& -\frac{2}{\bar{\rho}}\left(\frac{\partial \overline{u^{\prime} p^{\prime}}}{\partial x}+\frac{\partial \overline{v^{\prime} p^{\prime}}}{\partial y}\right)-2\left(\varepsilon_{1}+\varepsilon_{2}\right)
\end{aligned}
$$

It is generally admitted (Stull, 1988) that the transport terms of the pressure are lower than the ones relating to the turbulent kinetic energy. Thus, it can be written:

$$
\begin{aligned}
\frac{\partial}{\partial x}\left(\overline{u^{\prime} v^{\prime 2}}+\frac{2}{\bar{\rho}} \overline{u^{\prime} p^{\prime}}\right) & \approx \frac{\partial \overline{u^{\prime} v^{\prime 2}}}{\partial x} \quad \text { and } \\
\frac{\partial}{\partial y}\left(\overline{v^{\prime 3}}+\frac{2}{\bar{\rho}} \overline{v^{\prime} p^{\prime}}\right) & \approx \frac{\partial \overline{v^{\prime 3}}}{\partial y}
\end{aligned}
$$

Thus, Eq. (A3) becomes:

$$
\begin{aligned}
\bar{u} \frac{\partial\left(\overline{u^{\prime 2}}+\overline{v^{\prime 2}}\right)}{\partial x}= & -2\left(\overline{u^{\prime 2}} \frac{\partial \bar{u}}{\partial x}+\overline{u^{\prime} v^{\prime}} \frac{\partial \bar{u}}{\partial y}+\overline{u^{\prime} w^{\prime}} \frac{\partial \bar{u}}{\partial z}\right) \\
& -\left(\frac{\partial \overline{u^{\prime 3}}}{\partial x}+\frac{\partial \overline{v^{\prime} u^{\prime 2}}}{\partial y}+\frac{\partial \overline{w^{\prime} u^{\prime 2}}}{\partial z}\right)+ \\
& -\left(\frac{\partial \overline{u^{\prime} v^{\prime 2}}}{\partial x}+\frac{\partial \overline{v^{\prime 3}}}{\partial y}+\frac{\partial \overline{w^{\prime} v^{\prime 2}}}{\partial z}\right) \\
& -2\left(\varepsilon_{1}+\varepsilon_{2}\right)
\end{aligned}
$$

\section{Appendix B}

Equation (15) is expressed:

$z^{2} \frac{\partial^{2}(\bar{e})^{3 / 2}}{\partial z^{2}}+z \frac{\partial(\bar{e})^{3 / 2}}{\partial z}-\frac{3 C_{\varepsilon}}{2 k^{2} C_{K}}(\bar{e})^{3 / 2}=-\frac{3 U_{*}^{3}}{2 k^{2} C_{K}}$

otherwise:

$x^{2} f^{\prime \prime}(x)+x f^{\prime}(x)+a f(x)=b$

with:

$x=z$ and $f(x)=(\bar{e})^{3 / 2}$

$a=\frac{-3 C_{\varepsilon}}{2 k^{2} C_{K}}$ and $b=\frac{-3 U_{*}^{3}}{2 k^{2} C_{K}}$

Equation (B2) can be rewritten:

$x^{2} f^{\prime \prime}(x)+x f^{\prime}(x)+a\left(f(x)-\frac{b}{a}\right)=0$
Assuming:

$g(x)=f(x)-\frac{b}{a}$

we have:

$x^{2} g ”(x)+x g^{\prime}(x)+a g(x)=0$

It also can be assumed:

$g(x)=x^{n} h(x)$

which gives:

$x^{n+2} h^{\prime \prime}(x)+(2 n+1) x^{n+1} h^{\prime}(x)+\left(n^{2}+a\right) x^{n} h(x)=0$

otherwise:

$x^{2} h^{\prime \prime}(x)+(2 n+1) x h^{\prime}(x)=0$

with:

$n^{2}=-a=\frac{3 C_{\varepsilon}}{2 k^{2} C_{K}}$

Thus, it gives:

$x h^{\prime \prime}(x)+(2 n+1) h^{\prime}(x)=0$

otherwise:

$\left(x h^{\prime}(x)\right)^{\prime}+2 n h^{\prime}(x)=0$

which gives:

$x h^{\prime}(x)+2 n h(x)=C_{1}$

otherwise:

$\frac{h^{\prime}(x)}{C_{1}-2 n h(x)}=\frac{1}{x}$

Integrating the previous equation, we have:

$\ln \left[C_{1}-2 n h(x)\right]=-2 n \ln (x)+C_{3}$

After arrangements, we obtain:

$f(x)=C_{5} x^{n}+C_{6} x^{-n}+\frac{b}{a}$

Which leads to:

$\frac{\bar{e}}{U_{*}^{2}}=\left(\frac{1}{C_{\varepsilon}}+C_{7} z^{n}+C_{8} z^{-n}\right)^{2 / 3}$

with:

$n=\frac{1}{k} \sqrt{\frac{3 C_{\varepsilon}}{2 C_{K}}}$ 


\section{Appendix C}

In dealing with the mean wind velocity profile, two kinds of relationship are indifferently proposed and used, i.e. the power relationship and the logarithmic one. These relationships are:

1. The power relationship

$$
\frac{\overline{u(z)}}{\overline{u\left(z_{\text {ref }}\right)}}=\left(\frac{z}{z_{\text {ref }}}\right)^{\alpha}
$$

where

$-\overline{u(z)}$ is the mean wind velocity at level $z$

$-\overline{u\left(z_{\mathrm{ref}}\right)}$ is the mean wind velocity at level of reference $z_{\text {ref }}$

- $\alpha$ is the power law exponent, generally taken to $1 / 7$ (or 0.143 ).

2. The logarithmic relationship

$$
\frac{\overline{u(z)}}{U_{*}}=\frac{1}{k} \ln \left(\frac{z}{z_{0}}\right)
$$

where

$-\overline{u(z)}$ is the mean wind velocity at level $z$

- $U_{*}$ is the friction velocity

- $Z_{0}$ Roughness length

- $k$ the Von Karman's constant, equal to 0.4.

\section{Appendix D}

Brief description of MW method (i.e. Statistical Method for the Calculation of the Dynamic Parameters of the ASL and the Energy Balance).

The goal of the method is the determination of the dynamic parameters of the ASL (i.e. $U_{*}, \theta_{*}, q_{*}, Z_{0 m}, L$ ), by taking into account the measurement uncertainties relating to the measurement of different parameters and by using the energy balance, as well as the information pertaining to the net radiation and the heat flux into ground.

For a naked ground and while ignoring the advection effect, the steady state equation of the energy balance is:

$H+\lambda E=-(R n+G)$

where $H, E, G, R n$ and $\lambda$ represent, respectively, the flux of sensible heat, evaporation, heat into ground, net radiation and latent heat of vaporization.

Using the Monin-Obukhov similarity theory, and taking into account the effect of water vapor on the atmospheric stability (Brook, 1978; Busch, 1973; Riehl et al., 1978) and the attribution of different roughness lengths for momentum, heat and humidity equations (Brutsaert, 1975; Garrat et Hicks, 1973; Mascart et al., 1995; Wood et Mason, 1991), the profiles of wind, temperature and humidity, specific to the turbulent flow of atmospheric air in the ASL are described through:

$$
\begin{aligned}
\bar{u}(z) & =\frac{u_{*}}{k}\left[\ln \left(\frac{z}{z_{0 m}}\right)-\Psi_{u}\left(\frac{z}{L}\right)+\Psi_{u}\left(\frac{z_{0 m}}{L}\right)\right] \\
\overline{\Delta \theta} & =\bar{\theta}\left(z_{2}\right)-\bar{\theta}\left(z_{1}\right) \\
& =\frac{\theta_{*}}{k}\left[\ln \left(\frac{z_{2}}{z_{1}}\right)-\Psi_{\theta}\left(\frac{z_{2}}{L}\right)+\Psi_{\theta}\left(\frac{z_{1}}{L}\right)\right] \\
\overline{\Delta q} & =\bar{q}\left(z_{2}\right)-\bar{q}\left(z_{1}\right) \\
& =\frac{q_{*}}{k}\left[\ln \left(\frac{z_{2}}{z_{1}}\right)-\Psi_{q}\left(\frac{z_{2}}{L}\right)+\Psi_{q}\left(\frac{z_{1}}{L}\right)\right]
\end{aligned}
$$

with

$L=\frac{u_{*}^{2} \overline{\theta_{v}}}{k g \theta_{*}} \approx \frac{u_{*}^{2} \bar{\theta}(1+0.608 \bar{q})}{k g\left(\theta_{*}+0.608 \bar{\theta} q_{*}\right)}$

The roughness length $Z_{0 m}$, which is a local parameter bound to the ground surface, must be considered as an empirical coefficient in Eq. (D2a).

Many kinds of stability functions can be utilized for the resolution of these equations.

The temperature and humidity specific scales are bound to the sensible and latent heats through:

$$
\begin{aligned}
H & =c_{p} \rho u_{*} \theta_{v}^{*} \\
E & =\rho u_{*} q_{*}
\end{aligned}
$$

Equation (D1) is taken into account by adding an equation evaluating the gap between the evaluated flux of heat (i.e. $H+\lambda E$ ) and the radiation flux (i.e. $R n+G$ ):

$\delta=R n+G+c_{p} \rho u_{*} \theta_{v}^{*}+\lambda \rho u_{*} q_{*}$

With 5 points of wind profile, a temperature gradient, a humidity gradient and an energy balance equation, one has 8 equations for 4 unknown parameters, i.e. $u_{*}, \theta_{*}, q_{*}$ and $Z_{0 m}$, the Monin-Obukhov length deduced from 3 first previous parameters. This leads to the utilization of the mathematical technique of optimization.

As the roughness length and the friction velocity only appear in Eq. (D2a), it is more convenient to add supplementary equations in order to make the calculation of $Z_{0 m}$ more accurate. This can be obtained by expressing the profile of the mean wind velocity between two levels, as it follows:

$$
\begin{aligned}
\Delta \bar{u}_{i}^{j} & =\bar{u}\left(z_{i}\right)-\bar{u}\left(z_{j}\right) \\
& =\frac{u_{*}}{k}\left[\ln \left(\frac{z_{i}}{z_{j}}\right)-\Psi_{m}\left(\frac{z_{i}}{L}\right)+\Psi_{m}\left(\frac{z_{j}}{L}\right)\right]
\end{aligned}
$$


where the index " $i$ " is taken $1 \leq i \leq 5$ while " $j$ " is taken $i<j \leq 5$.

Finally, there are 4 unknowns for 17 equations in the system make up with Eqs. (D2a), (D2b), (D2c), (D4) and (D5).

Acknowledgements. The authors thank The European Commission-Environment and Climate Programme DG XII, which sponsored the WELSONS experiment under contract $n{ }^{\circ}$ ENV4-CT95-0182; Emeritus Gilles de Rosny for the detailed inspection of this paper; reviewers of the paper, who help very much in improving its quality.

Topical Editor F. D'Andrea thanks R. A. Brown and another anonymous referee for their help in evaluating this paper.

\section{References}

André, J. C., De Moor, G., Lacarrere, P., Therry, G., and Du Vachat, R.: Modelling the 24-hr Evolution of the Mean and Turbulent Structures of the Planetary Boundary Layer, J. Atmos. Sci., 35, 1861-1883, 1978.

Brook, R. R.: The influence of water vapor fluctuations on turbulent fluxes, Bound.-Lay. Meteorol., 15, 481-487, 1978.

Brutsaert, W.: The roughness length for water vapor, sensible heat, and others scalars, J. Atmos. Sci., 32, 2028-2031, 1975.

Busch, N. E.: On the mechanics of atmospheric turbulence, in: Workshop on Micrometeorology, edited by: Haugen, D. A., Am. Meteorol. Soc., Boston, Massachusetts, 392 pp., 1973.

Carlotti, P.: Distorted turbulence near rigid boundaries, $\mathrm{PhD}$ thesis, University of Cambridge, 185 pp., 2001.

De Moor, G.: Les théories de la turbulence dans la couche limite atmosphérique, Direction de la Météorologie, 312 pp., 1983.

Drobinski, P., Carlotti, P., Newsom, R. K., Banta, R. M., Foster, R. C., and Redelsperger, J.-L.: The structure of the near-neutral atmospheric surface layer, J. Atmos. Sci., 61, 699-714, 2004.

Drobinski, P., Carlotti, P., Newsom, R. K., Banta, R. M., Foster, R. C., and Redelsperger, J.-L.: Corrigendum of the above paper, J. Atmos. Sci., 61, 2400, doi:10.1175/15200469(2004)061<2400:C>2.0.CO;2, 2004b.

Frangi, J. P. and Poullain, P.: Un système d'acquisition haute vitesse de données dynamiques, associé à une station de mesure du bilan d'énergie de surface, Sécheresse, 8, 70 p., 1997.

Frangi, J.-P. and Richard, D. C.: The WELSONS experiment: overview and presentation of first results on the surface atmospheric boundary-layer in semiarid Spain, Ann. Geophys., 18, 365-384, 2000, http://www.ann-geophys.net/18/365/2000/.

Fritschen, L. J. and Gay, L. W.: Environmental instrumentation, Springer-Verlag, New York, 1979.

Garratt, J. R.: The atmospheric Boundary Layer, Cambridge Atmospheric and Space Science Series, 316 pp., 1992.

Garratt, J. R. and Hicks, B. B.: Momentum, heat and water vapour transfer to and from natural and artificial surfaces, Q. J. Roy. Meteor. Soc., 99, 680-687, 1973.

Gomes, L., Arrue, J. L., Lopez, M. V., Sterk, G., Richard, D., Gracia, R., Sabre, J. M., Gaudichet, A., and Frangi, J. P.: Wind erosion in a semiarid area of Spain: the WELSONS project, Catena, 52, 235-256. doi:10.1016/S0341-8162(03)00016-X, 2003.

Grant, A. L. M.: Observations of boundary layer structure made during the 1981 KONTUR experiment, Q. J. Roy. Meteor. Soc., 112, 825-841, 1986.
Grant, A. L. M.: The structure of turbulence in the near-neutral atmospheric boundary layer, J. Atmos. Sci., 49, 226-239, 1992.

Guyot, G.: Climatologie de l'environnement - De la plante aux écosystèmes, Masson (Ed.), Paris, coll. SV, 505 pp., 1997.

Hedde, T. and Durand, P.: Turbulence intensities and bulk coefficients in the surface layer above the sea, Bound.-Lay. Meteorol., 71, 415-432, 1994.

Högström, U.: Analysis of turbulence structure in the surface layer with modified similarity formulation for near neutral conditions, J. Atmos. Sci., 47(16), 1949-1972, 1990.

Hunt, J. C. R. and Carlotti, P.: Statistical structure at the wall of the high Reynolds number turbulent boundary layer, Flow, Turbulence and Combustion, 66, 453-475, 2001.

Hunt, J. C. R. and Morrison, J. F.: Eddy Structure in Turbulent Boundary Layers, Eur. J. Mech. B/Fluids, 19, 673-694, 2000.

Idé. H.: Dynamics and turbulence in the Sahelian surface atmospheric boundary layer (STARS experiment), Thesis Nr 982, University Paul Sabatier, Toulouse, France, 228 pp., 1991 (in French).

Kaimal, J. C. and Finnigan, J. J.: Atmospheric Boundary Layer Flows, Their Structure and Measurement, Oxford University Press, 289 pp., Edition 1994, 1994.

Lopez, M. V., Arrue, J.-L., and Sanchez-Giron, V.: A comparison between seasonal changes in soil water storage and penetration resistance under conventional and conservation tillage systems in Aragon, Soil Tillage Res., 37, 251-271, 1996.

Louis, J. F., Weill, A., and Vidal-Madjar, D.: Dissipation length in stable layers, Bound.-Lay. Meteorol., 25, 229-243, 1983.

Lumley, J. L. and Panofsky, H. A.: The structure of atmospheric turbulence, Wiley-Interscience, New York, 239 pp., 1964.

Mascart, P., Noilhan, J., and Giordani, H.: A modified parameterization of flux-profile relationships in the surface layer using different roughness length values for heat and momentum, Bound.Lay. Meteorol., 72, 331-344, 1995.

Meyers, T. P. and Baldocchi, D. D.: The budget of turbulent kinetic energy and Reynolds stress within and above a deciduous forest, Agric. For. Meteor., 53, 207-222, 1991.

Monin, A. S. and Yaglom, A. M.: Statistical fluids mechanics: mechanics of turbulence, vol 1. The MIT Press, 1971.

Moraes, O. L. L. and Epstein, M.: The velocity spectra in the stable surface layer, Bound.-Lay. Meteorol., 40, 407-414, 1987.

Pahlow, M., Parlange, M. B., and Porté-Agel, F.: On the MoninObukhov similarity in the stable atmospheric boundary layer, Bound.-Lay. Meteorol., 99, 225-248, 2001.

Panofsky, H. A., Tennnekes, H., Lenschow, D. H., and Wyngaard, J. C.: The characteristics of turbulent velocity components in the surface layer under convective conditions, Bound.-Lay. Meteorol., 11, 355-361, 1977.

Raupach, M. R., Coppin, P. A., and Legg, B. J.: Experiments on scalar dispersion within a model plant canopy. Part I: The turbulence structure, Bound.-Lay. Meteor., 35, 21-52, 1986.

Redelsperger, J. L., Mahé, F., and Carlotti, P.: A simple and general subgrid model suitable both for surface layer and freestream turbulence, Bound.-Lay. Meteorol., 101(3), 375-408, doi:10.1023/A:1019206001292, 2001.

Richard, D. C.: Contribution to the study of the Spanish semi-arid ASL, within the framework of WELSONS Project, in French, Thesis no. 2000PA077201, University Denis Diderot, Paris 7, France, 303 pp., 2000. 
Riehl, H., Greenhut, G., and Bean, B.: Energy transfer in the tropical subcloud layer measured with DC-6 aircraft during GATE, Tellus, 30, 524-536, 1978.

Said, F.: Experimental study of the marine boundary layer: Turbulence structure and surface fluxes (TOSCANE-T Experiment), Thesis No. 248, University Paul Sabatier, Toulouse, France, 335 pp., 1988 (in French).

Solari, G.: Turbulence modelling for gust loading, J. Struct. Engin, ASCE, 113(7), 1150-1569, 1987.

Stull, R. B.: An Introduction to Boundary Layer Meteorology, Atmospheric Sciences Library, Kluwer Academic Publishers, 670 pp., Edition of 1999, 1988.

Wilson, R. N. and Shaw, R. H.: A higher order closure model for canopy flow, J. Appl. Meteor., 16, 1197-1205, 1977.

Wood, N. and Mason, P.: The influence of static stability on the effective roughness lengths for momentum and heat transfer, Q. J. Roy. Meteor. Soc., 117, 1025-1056, 1991.

Wyngaard, J. C. and Coté, O. R.: The budgets of turbulent kinetic energy and temperature variance in the atmospheric surface layer, J. Atmos. Sci., 28, 190-201, 1971.
Yadav, A. K., Raman, S., and Niyogi, D. D. S.: A note on the estimation of eddy diffusivity and dissipation length in low winds over a tropical urban terrain, Pure Appl. Geophys., 160, 395404, 2003.

Yahaya, S.: Dynamique de la couche limite de surface semiaride: Approche des caractéristiques turbulentes par anémomérie à coupelles et effet des traitements de surface du sol, Thse de doctorat de l'Université Paris 7 - Denis Diderot, 248 p., 2004.

Yahaya, S. and Frangi, J. P.: Cup anemometer response to the wind turbulence-measurement of the horizontal wind variance, Ann. Geophys., 22, 3363-3374, 2004, http://www.ann-geophys.net/22/3363/2004/.

Yahaya, S., Frangi, J. P., and Richard, D. C.: Turbulent characteristics of a semiarid atmospheric surface layer from cup anemometers - effects of soil tillage treatment (Northern Spain), Ann. Geophys., 21, 2119-2131, 2003, http://www.ann-geophys.net/21/2119/2003/. 